\title{
Awareness and attitudes towards clinical trials among Polish oncological patients who had never participated in a clinical trial
}

\author{
Anna Staniszewska ${ }^{1, A, D, F}$, Adriana Lubiejewska ${ }^{2, B}$, Aleksandra Czerw 3,D, Marta Dąbrowska-Bender, \\ Aneta Duda-Zalewska ${ }^{3, C}$, Dominik Olejniczak ${ }^{3, B}$, Grzegorz Juszczyk ${ }^{3, E}$, Magdalena Bujalska-Zadrożny ${ }^{4, F}$ \\ ${ }^{1}$ Department of Experimental and Clinical Pharmacology, Medical University of Warsaw, Poland \\ ${ }^{2}$ ICON Clinical Research, Warszawa, Poland \\ ${ }^{3}$ Department of Public Health, Medical University of Warsaw, Poland \\ ${ }^{4}$ Department of Pharmacodynamics, Medical University of Warsaw, Poland \\ A - research concept and design; B - collection and/or assembly of data; C - data analysis and interpretation; \\ $\mathrm{D}$ - writing the article; $\mathrm{E}$ - critical revision of the article; $\mathrm{F}$ - final approval of the article
}

\author{
Address for correspondence \\ Anna Staniszewska \\ E-mail: anna.staniszewska@wum.edu.pl \\ Funding sources \\ None declared \\ Conflict of interest \\ None declared

\section{Acknowledgements} \\ We would like to thank the patients who, regardless \\ of their difficult life situation, were willing to share \\ their attitudes towards the doctors and nurses \\ at the Maria Skłodowska-Curie Memorial Cancer \\ Center and Institute of Oncology in Warszawa \\ in order to allow us to conduct research.
}

Received on September 17, 2016

Reviewed on October 6, 2016

Accepted on February 2, 2017

\begin{abstract}
Background. Participation in a clinical trial significantly shortens waiting time associated with receiving specialist care. Furthermore, it may be the case that, through clinical trials, subjects can access medicines that are not typically available in Poland.

Objectives. The aim of this study was to determine the opinions of oncological patients about clinical trials.

Material and methods. The research has been carried out during the years 2014-2016. A proprietary questionnaire consisting of 10 closed, single and multiple choice questions about awareness and perceptions of clinical trials, and 5 questions concerning demographic information was used. A group of 256 patients with cancer (54\% women, 46\% men), aged 21-77 years, was surveyed.

Results. Respondents were statistically more likely to decide to participate in a clinical trial as oncological patients than the healthy volunteers (Pearson's $x^{2}$ test $p=0.00006$ ). The desire to qualify for clinical trials in no way depends on the knowledge of side effects (Pearson's $x^{2}$ test $p=0.16796$ ).

Conclusions. Our study found that the patients' awareness about clinical trials varied. However, a positive attitude towards research was visible. The main identified barriers to clinical trial participation were fear of possible side effects. Most patients regarded clinical trials as useful, and considered that they are conducted to introduce new treatment/new drug.
\end{abstract}

Key words: clinical trials, patient attitudes, awareness, perception, patients with cancer

DOI

10.17219/acem/68762

Copyright

Copyright by Author(s)

This is an article distributed under the terms of the

Creative Commons Attribution Non-Commercial License

(http://creativecommons.org/licenses/by-nc-nd/4.0/) 


\section{Introduction}

The era of randomized cancer clinical trials began in 1958 with the first use of systemic therapy following a radical mastectomy in the treatment of breast cancer. ${ }^{1}$ In 2014 in Poland, there were 396 new clinical trials recorded. Approximately, $1 / 4$ of patients in clinical trials in Poland are enrolled in oncology studies (23\% in 2014)., ${ }^{2,3}$ Oncology is a frequent area of clinical research in Poland due to many factors. Firstly, in Poland, access to the national healthcare system is limited, and medications are expensive; hence, with the offer of better medical care, free drugs and diagnostic procedures, patient recruitment in clinical trials is very high. This factor is particularly important when treating patients in areas where the availability of effective drugs is limited at this stage of the development of medicine (i.e., oncology). Secondly, the high motivation to participate in clinical trials may also result from the relatively long time patients have to wait to see a specialist in Poland. Participation in a clinical trial, therefore, significantly shortens the average time associated with receiving specialist care. Furthermore, it may be the case that, through clinical trials, subjects can access medicines that are not typically available in Poland.

\section{Material and methods}

\section{Sample and place of study}

The prospective study was conducted among 284 patients of Maria Skłodowska-Curie Memorial Cancer Center and Institute of Oncology in Warszawa, Poland in 2014-2016. Patients were recruited to collect a mixture of tumor types (soft tissue sarcoma, bone sarcoma, malignant melanoma, gastrointestinal stromal tumor, breast cancer, and lung cancer) and cancer stages; study included patients who had never participated in a clinical trial. Exclusion criteria included age $<18$ years. We selected our sample on the basis of respondents' availability. We conducted the study with patients available at a given time and place at the Maria Skłodowska-Curie Memorial Cancer Center and Institute of Oncology in Warszawa, based on the randomness of their visits to the Institute. The sample included patients of different sociodemographic data: age and gender, place of residence, marital status, and educational stage. Participation in the survey was voluntary and anonymous. Out of 284 selected patients, 256 (90\%) agreed to participate in the study and completed the questionnaire. Analysis was based on responses from these 256 respondents. We analyzed all subjects as a group, regardless of the type of cancer.

\section{Instruments}

We applied the "Paper and Pencil Interview" (PAPI) technique. This survey-based study was performed using the authors' own questionnaire; it included 10 closed questions about the awareness and perceptions of clinical trials as well as single- and multiple-choice questions; 5 questions concerning demographic information. The majority of questions in our questionnaire were adapted from a literature review and previous similar studies. All the possible answers are shown in Tables 1-4 and Fig. 1.

\section{Ethics}

The Ethical Committee consent for the presented research is not required. According to the statement of the Ethical Committee of the Medical University of Warsaw: "The Committee does not provide opinions on surveys, retrospective studies, or other non-invasive research." 4

\section{Data analysis}

The data was collected in a Microsoft Excel database. Survey responses were aggregated into frequencies and percentages. Statistical analysis was performed using STATISTICA v. 10 software (StatSoft, Tulsa, USA). Descriptive statistics of respondent demographics, awareness of clinical trials, and a willingness to participate in clinical trials were analyzed. Associations among the variables were evaluated by $\mathrm{X}^{2}$ test. A value of $\mathrm{p}<0.05$ was considered statistically significant.

\section{Results}

\section{Socio-demographic characteristics of patients}

The study was performed in 256 patients with cancer, including 138 women (54\%) and 118 men (46\%). The mean age of respondents was 46 (range: $21-77$ years). The main part of the population taking part in the study comprised married persons (44\%); with regard to other previously mentioned sociodemographic data, $38 \%$ of patients had secondary education, and about $75 \%$ lived in an urban area. Table 1 presents the socio-demographic characteristics of the patient population.

\section{Patients' attitudes towards clinical trials}

In terms of knowledge and awareness of clinical trials, $69.9 \%$ of the participants had previously heard about clinical trials, but $64.8 \%$ had an interest in participating in cancer clinical trials, and only $53.9 \%$ had an interest in participating in clinical trials as healthy volunteers. Respondents were statistically more likely to decide to participate in a clinical trial as oncological patients than as healthy volunteers (Pearson's $X^{2}$ test $\mathrm{p}=0.00006$ ). Other factors, including age, gender, educational level, and resident area were not significantly associated with willingness to participate in clinical trials $(\mathrm{p}>0.05)$. Most 
respondents (60.2\%) said their doctors had not bgought up the option of taking part in a clinical trial during the treatment planning phase. In the overall group $(n=256), 94.1 \%$ of the patients regarded clinical trials as useful. Most patients $(89.1 \%)$ were aware that during the clinical trial they might experience side effects - Table 2.

Table 1. Sociodemographic characteristics of patients participating in the survey

\begin{tabular}{|c|c|c|}
\hline Variables & $\mathrm{n}$ & $\%$ \\
\hline Total & 256 & 100 \\
\hline $\begin{array}{l}\text { Gender } \\
\text { female } \\
\text { male }\end{array}$ & $\begin{array}{l}138 \\
118\end{array}$ & $\begin{array}{l}54 \\
46\end{array}$ \\
\hline $\begin{array}{l}\text { Age } \\
\text { mean (SD) } \\
\text { range }\end{array}$ & \multicolumn{2}{|c|}{$\begin{array}{l}46(12) \text { years } \\
21-77 \text { years }\end{array}$} \\
\hline $\begin{array}{l}\text { Marital status } \\
\text { single } \\
\text { married } \\
\text { widowed }\end{array}$ & $\begin{array}{l}105 \\
113 \\
38\end{array}$ & $\begin{array}{l}41 \\
44 \\
15\end{array}$ \\
\hline $\begin{array}{l}\text { Education } \\
\text { primary } \\
\text { vocational } \\
\text { secondary } \\
\text { university }\end{array}$ & $\begin{array}{l}46 \\
46 \\
97 \\
67\end{array}$ & $\begin{array}{l}18 \\
18 \\
38 \\
26\end{array}$ \\
\hline $\begin{array}{c}\text { Place of residence } \\
\text { urban area } \\
\text { rural area }\end{array}$ & $\begin{array}{c}192 \\
54\end{array}$ & $\begin{array}{l}75 \\
25\end{array}$ \\
\hline
\end{tabular}

The desire to qualify for clinical trials in no way depends on the knowledge of the side effects (Pearson's $\chi^{2}$ test $\mathrm{p}=0.16796)$.

The most frequent source of information about clinical trials was mass media (94\%), other patients who took part in clinical trials before (46\%), and physicians (37\%) - Fig. 1.

The survey group recognized the benefits of clinical trials, such as treatment that may be more effective than the standard approach (85.2\%), and regular and careful attention from some of the best cancer doctors (10.2\%). Among the more frequently cited barriers were the fear of possible side effects (69.1\%) and frequent hospital visits (12.9\%) - Table 3.

Clinical trials were more often associated with positive factors; they were most often associated with the introduction of new therapy (62.1\%) and the advancement of medical knowledge (46.1\%). However, $46.1 \%$ of respondents indicated that patients in clinical trials are "treated like guinea pigs" - Table 4 .

\section{Discussion}

In our study, only $69.9 \%$ of respondents had previously heard about clinical trials. Similar results were obtained among rural Latinos, where that percentage was $68 \% .^{5}$ However, a previous public opinion study conducted in Poland in $2004(n=1003)$ showed that only $28 \%$

Table 2. Attitudes about cancer clinical trials among respondents

\begin{tabular}{|c|c|c|c|}
\hline \multirow[b]{2}{*}{ Question } & \multicolumn{3}{|c|}{ Answers } \\
\hline & $\begin{array}{c}\text { yes } \\
n(\%)\end{array}$ & $\begin{array}{c}\text { no } \\
\mathrm{n}(\%)\end{array}$ & $\begin{array}{c}\text { do not know } \\
n(\%)\end{array}$ \\
\hline Have you ever heard of cancer clinical research studies? & $179(69.9)$ & $18(7.0)$ & $59(23.1)$ \\
\hline Would you be interested in participating in a cancer clinical research study? & $166(64.8)$ & $90(35.2)$ & - \\
\hline Would you be interested in participating in a clinical trial as a healthy volunteer? & $138(53.9)$ & $90(35.2)$ & $28(10.9)$ \\
\hline Have you ever talked to your doctor about participating in clinical trials? & $102(39.8)$ & $154(60.2)$ & - \\
\hline Do you think clinical trials are useful? & $241(94.1)$ & $5(1.9)$ & $10(4.0)$ \\
\hline During the clinical trial, would you experience side effects? & $228(89.1)$ & $28(10.9)$ & - \\
\hline
\end{tabular}

Table 3. Benefits and barriers for participation in a clinical trial

\begin{tabular}{|c|c|c|}
\hline Question & Answer & n (\%) \\
\hline \multirow{4}{*}{ Benefits of clinical trial participation } & treatment that may be more effective than the standard approach & $218(85.2)$ \\
\hline & regular and careful attention from some of the best cancer doctors & $26(10.2)$ \\
\hline & economic benefit & $7(2.7)$ \\
\hline & other & $5(1.9)$ \\
\hline \multirow{5}{*}{ Barriers to participation in clinical trials } & fear of possible side effects & $177(69.1)$ \\
\hline & frequent hospital visits & $33(12.9)$ \\
\hline & inconvenient follow-up location & $14(5.5)$ \\
\hline & lack of trust in doctor/pharmaceutical companies & $7(2.7)$ \\
\hline & other & $25(9.8)$ \\
\hline
\end{tabular}


Table 4. Factors associated with clinical trials

\begin{tabular}{|l|c|c|}
\hline \multicolumn{1}{|c|}{ Variables } & yes & Answers \\
\cline { 2 - 3 } & $n(\%)$ & $n$ no \\
\hline Contribution to medicine & $118(46.1)$ & $138(53.9)$ \\
\hline Feeling like a guinea pig/being experimented on & $118(46.1)$ & $138(54.9)$ \\
\hline Introduction of new drugs/therapy & $159(62.1)$ & $97(37.9)$ \\
\hline Improved health for the clinical trial participants & $105(41.0)$ & $231(59.0)$ \\
\hline Risk, danger for clinical trial participants & $74(28.9)$ & $182(71.1)$ \\
\hline Financial benefit for patients & $38(14.8)$ & $218(85.2)$ \\
\hline Novelty & $23(9.0)$ & $233(91.0)$ \\
\hline Unfair effect of pharmaceutical companies & $18(7.0)$ & $238(93.0)$ \\
\hline Financial benefit for physician & $7(2.7)$ & $249(97.3)$ \\
\hline Deterioration in health for the clinical trial participants & $7(2.7)$ & $249(97.3)$ \\
\hline
\end{tabular}

of respondents, at any time, had heard about the clinical trials. ${ }^{6}$ The differences in the results obtained in our country can be explained by the fact that our study was conducted 10 years later, which may indicate that clinical trials in Poland are more popularized now.

In this survey, $64.8 \%$ of the interviewed subjects indicated willingness to participate in cancer clinical trials; however, only $53.9 \%$ indicated willingness to participate in clinical trials as a healthy volunteer. In a study conducted in Saudi Arabia, 61\% of the 117 interviewed subjects who were aware of clinical trials expressed their willingness to participate in them. ${ }^{7}$ Nevertheless, in the study conducted in India, $58.9 \%$ of the participants expressed willingness to participate in clinical trials. ${ }^{8}$ In another study in the United States, $44 \%$ of patients demonstrated willingness to participate or have already enrolled in clinical trials, whereas in the study in Great Britain ( $n=1040)$, only $30.4 \%$ of the respondents conveyed their enthusiasm to participate in clinical trials. ${ }^{9,10}$ In a previously cited Polish study, the number of people willing to participate in a clinical trial with regard to disease increases about 5-fold compared with a desire to participate as a healthy volunteer (from $15 \%$ to $71 \%$ ). ${ }^{6}$ The potential benefit of participating in a clinical trial for an oncological patient is the access to promising new treatments often not available outside the clinical trial setting - this may explain the difference. Possibly, the main reason people lack willingness to participate in a clinical trial is that they are not aware that the studies are an option for them. Our research has shown that $60.2 \%$ of the patients had not discussed participating in clinical trials with their doctor. This is consistent with the results of another study indicating that $73 \%$ of patients did not recall discussing clinical trial participation with their doctor. ${ }^{11}$

In our study, $84 \%$ of all respondents pointed to mass media as the most common source of information on clinical trials. For $46 \%$, it were other patients who, prior to participation in clinical trials, were the primary source

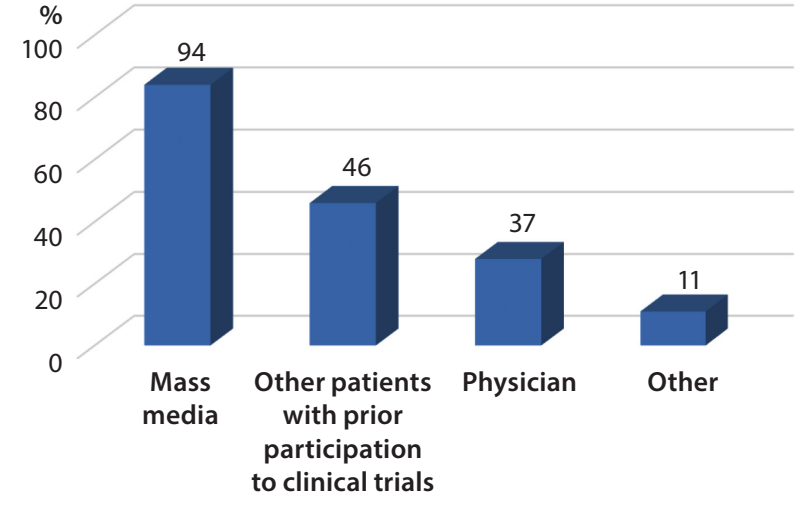

Fig. 1. Source of knowledge about clinical trials among respondents (The data does not give a total of 100\%, because the respondents could choose multiple answers)

of that information. An American study from 2015 showed that people aware of clinical trials, most learned about clinical trials online (58\%). ${ }^{12}$ The Center for Information and Study on Clinical Research Participation (CISCRP), founded in 2013, showed that the Internet is the most common way of finding out about clinical trials. ${ }^{13}$

With regard to the recognition of clinical trials as important and necessary, $94.1 \%$ of the patients regarded clinical trials as useful, and admitted that participating in them can bring benefits; the respondents in a public opinion study also highly appreciated the need for clinical trials (71\%). ${ }^{6}$

The decision about whether to participate in clinical trial is very personal and depends on many factors, both positive and negative. In our study, one such factor is the fear of being treated like a guinea pig (46.1\%); on the other hand, equal number of respondents considered that participating in a clinical study contributes to medical knowledge. In another Polish study, $88 \%$ of the public opinion established the fact that there could be advances in medicine as a result. ${ }^{6}$ In addition, $62.1 \%$ of our study population stated that a clinical trial is conducted for the introduction 
of a new treatment/new drug. In turn, in the OMNIBUS study conducted in May 2010, most respondents (35\%) associated clinical trials with advances in medicine, and in a study by Shapiro et al., they also believed that clinical trials contribute to the development of medicine (63\%). ${ }^{14,15}$

Clinical trials can offer benefits for many people with cancer. The patients in our study said that clinical trials are an alternative treatment for the disease - clinical trial treatment was thought to be better than the standard treatment (85.2\%). Other studies have established that the most important benefits that encourage patients to participate in clinical trials are: the possibility of reducing one's chance of getting cancer and the possibility of preventing others from getting cancer in the future, the psychosocial benefits of trial participation, and also the possible benefit of treatment effectiveness. ${ }^{16,17}$

On the one hand, clinical trials are the basis for improvements in oncologic patient care, but on the other they have significant barriers. In our study, $69.1 \%$ of patients identified the fear of side effects as the greatest barrier to clinical trial participation, and $89.1 \%$ said that during clinical trials they may experience unexpected side effects. As many as $76 \%$ of the survey respondents of public opinion study claimed that participating in tests of a new drug may harm their health. ${ }^{6}$ Other barriers that discouraged patients from participating in clinical trials are fear, mistrust of the medical community, discouragement from oncologist or family physician, financial burden, difficulties in commuting, and lack of information. ${ }^{8}$ However, a survey done by the CISCRP in 2013 found that $94 \%$ of respondents believe clinical research is safe for those who participate in it. ${ }^{13}$

\section{Conclusions}

In conclusion, our study found that patient's awareness about clinical trials varied. However, a positive attitude towards research was visible. The main identified barrier was the fear of possible side effects. Most patients regarded clinical trials as useful, conducted to introduce a new treatment or drug. These results might be helpful for improving clinical researchers' understanding about clinical trial participants and useful when developing effective outreach strategies of recruitment for clinical trials.
This study is the first research on the awareness and attitudes towards clinical trials among oncological patients in Poland.

\section{References}

1. Streptomycin treatment of pulmonary tuberculosis. A Medical Research Council Investigation. BMJ. 1948;2(4582):769-782.

2. Gryz M. Badania kliniczne w Polsce. http://www.badaniaklinicznewpolsce.pl/download/gfx/infarma/pl/defaultopisy/83/105/1/dr_ michal_gryz.pdf. Accessed August 1, 2016.

3. Clinical Trials in Poland, www.infarma.pl/assets/files/2016/Clinical Trials_in_Poland_december_2015.pdf. Accessed September 5, 2016.

4. Detailed information and templates of documents of Ethics Committee of Medical University of Warsaw. http://komisjabioetyczna.wum. edu.pl/ content/szczeg\%C3\%B3\%C5\%82owe-informacje-orazwzory-dokument\%C3\%B3w. Accessed September 1, 2016.

5. Cupertino AP, Molina CSP, de los Rios JB, et al. Knowledge, awareness, and interest in cancer clinical trials among rural Latinos following brief education by Promotores de Salud. J Community Med Health Educ. 2015;5:358.

6. Badania kliniczne w Polsce - „eksperyment" na ludziach czy dla ludzi?. http://www.onboard.pl/data/file/pdf/raport_sektorowy_ badania_kliniczne_w_polsce.pdf. Accessed September 1, 2016.

7. Bazarbashi S, Hassan A, Eldin AM, Soudy H, Hussain F. Awareness and perceptions of clinical trials in cancer patients and their families in Saudi Arabia. J Cancer Educ. 2015;30:655-659.

8. Burt T, Dhillon S, Sharma P, et al. PARTAKE survey of public knowledge and perceptions of clinical research in India. PLoS One. 2013;8:e68666.

9. Byrne MM, Tannenbaum SL, Gluck S, Hurley J, Antoni M. Participation in cancer clinical trials: Why are patients not participating? Med Decis Making. 2014;34:116-126.

10. Mackenzie IS, Wei L, Rutherford D, et al. Promoting public awareness of randomised clinical trials using the media: The 'Get Randomised' campaign. Br J Clin Pharmacol. 2010;69:128-135.

11. Ramers-Verhoeven CW, Geipel GL, Howie M. New insights into public perceptions of cancer. Ecancermedicalscience. 2013;7:349.

12. National Poll: Clinical Research. Research America an Alliance for Discoveries in Health. https://www.researchamerica.org/sites/default/ files/uploads/June2013clinicaltrials.pdf. Accessed June 15, 2016.

13. Charts and Statistics: Useful information about clinical research before participating in a trial. https://www.ciscrp.org/education-center/ charts-and-statistics/before-participation/ Accessed January 2, 2016.

14. Badania kliniczne w Polsce - główne wyzwania. http://www.gcppl. org.pl/images/stories/pliki/opracowania/badania_kliniczne_2010. pdf. Accessed August 18, 2016.

15. Shapiro LJ, et al. Public Opinion About Clinical Trials. http://www.ljs. com/fileadmin/ljs-files/studies/Public_Opinion_about_Clinical_Trials_ARTICLE__1-22-07_.pdf?dp. Accessed August 26, 2016.

16. Hudmon KS, Love RR, Chamberlain RM. Perceived benefits of and barriers to participation in a phase I/II colon cancer chemoprevention trial. J Cancer Educ. 1999;14(2):83-87.

17. van Luijn HEM, Musschenga AW, Keus RN, Robinson WM, Aaronson NK. Assessment of the risk/benefit ratio of phase II cancer clinical trials by Institutional Review Board (IRB) members. Ann Oncol. 2002;13(8):1307-1313.

\section{Study limitations}

This study had limitations due to a single group and lack of a control group. Further research should be performed to compare the results of:

a) oncological patients who had never participated in a clinical trial vs oncological patients who have previously participated in a clinical trial;

b) oncological patients who had never participated in a clinical trial vs healthy individuals. 